\title{
Silica Fume and Fly Ash Admixed Can Help to Improve the PRC Durability Combine Microscopic Analysis
}

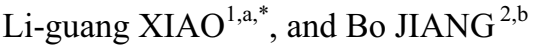 \\ ${ }^{1,2}$ College of Material Science and Engineering, Jilin Jianzhu University, Changchun, China \\ axlg627@163.com, ${ }^{\mathrm{b}} 13944083212 @ 163 . c o m$
}

\begin{abstract}
Silica fume/Fly ash RPC can greatly improve durability. When Silica fume to replace the same amount of $8 \%$ of the proportion of cement, re-mixed $15 \mathrm{~min}$ of mechanically activated Fly ash content of $10 \%$, by chloride ion flux detector measuring, complex doped than the reference RPC impermeability improved significantly; In addition, by using static nitrogen adsorption method showed, RPC internal pore structure determination, the hole integral volume was lower than the reference admixed RPC integral pore volume significantly; And combined SEM microscopic experimental methods, mixed of RPC internal structure and the formation mechanism analysis showed that, SF/FA complex fully embodies the synergy doped composites "Synergistic" principle.
\end{abstract}

\section{Introduction}

Reactive Powder Concrete (RPC) is an ultra high strength concrete. Due to the high strength, brittleness, under conditions of low water-cement ratio produces greater self shrinkage stress, causing internal micro defects produce concrete, serious impact on RPC durability. Therefore, this article by Silica fume mineral admixture and Fly ash mixed with complex, reducing internal defects RPC, thereby increasing its durability.

\section{Experimental Procedures}

\subsection{Raw Material Specifications}

Cement using P.O42.5R ordinary portland cement, specific surface area is $802.9 \mathrm{~m}^{2} / \mathrm{kg}$; Coarse, medium and fine grading of 1:4:10 quartz sand; Fly ash is a $45 \mu \mathrm{m}$ square hole sieve residue $19.3 \%$ after machine grinding $15 \mathrm{~min}$ measured, a specific surface area is $1454.5 \mathrm{~m}^{2} / \mathrm{kg}$; Silica fume $45 \mu \mathrm{m}$ square hole sieve margin used was $7.8 \%$, a specific surface area is $20379.7 \mathrm{~m}^{2} / \mathrm{kg}$; Reducing agent used is polycarboxylate superplasticizer.

\footnotetext{
*Corresponding author:xlg627@163.com
} 


\subsection{Laboratory Apparatus}

This experiment uses the instruments are: NEL-VJH concrete intelligent full water machine; NEL-PEU concrete electric flux meter; SF-150 type cement fineness of negative pressure sieve analysis instrument; V-Sorb 2800p high-performance automatic specific surface area and pore size tester; KNM-type II quick grinding machine; HY- $1600^{\circ} \mathrm{C}$ high temperature electric furnace energy saving; The type 554800 X-ray diffractometer; KYKY-2800 type B SEM scanning electronic microscope.

\section{Results and Discussion}

The experiment is adopt to the same amount of cement substitution method. It adopts to $\mathrm{SF}$ of the same amount to replace cement in other conditions unchanged. The ratio of single mixed SF are $4 \%, 6 \%, 8 \%, 10 \%$ and $12 \%$.

Experimentally determined the optimum dosage ratio of SF. With the same substitution method, FA replaces the mixed which is include of cement and silica fume. The ratio of fly ash content is $5 \%, 10 \%, 15 \%, 20 \%$ and $25 \%$. Basic mixing ratio of cement, sand, water, and polycarboxylate superplasticizer than the same, different dosage of SF and FA test result are shown in Fig.1 and Fig.2.

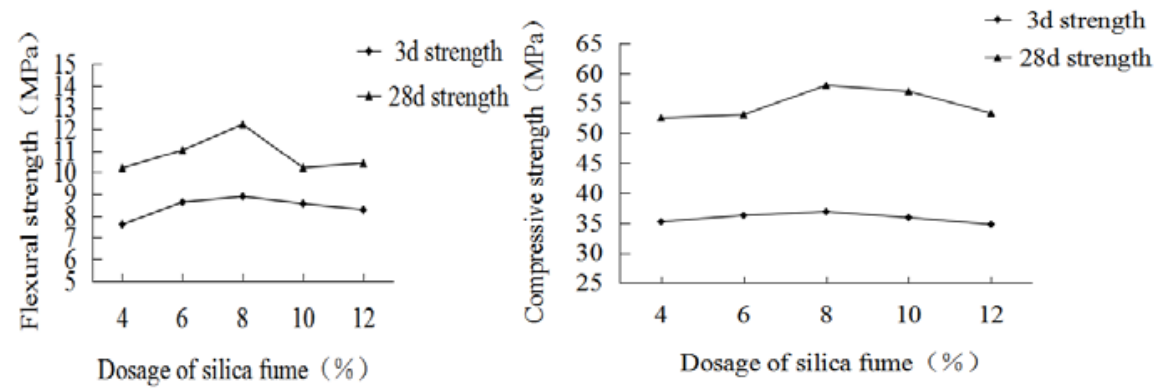

Fig.1 Effect of different dosage of SF on the flexural strength and compressive strength of RPC
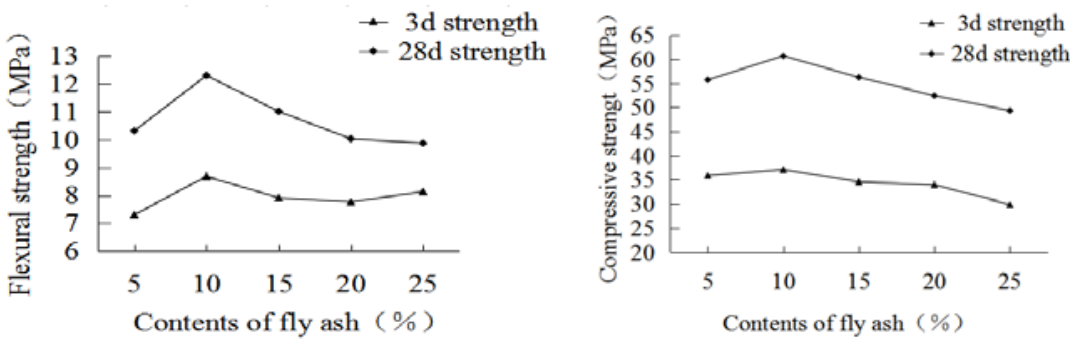

Fig.2 Effect of different contents of FA on the bending strength and compressive strength of RPC

As can be seen by Fig.1, after SF added, the mechanical strength of RPC has improved effect significantly, the early strength and late strength are both higher than the reference RPC strength. In SF, there are more than $90 \%$ of the active ingredient is $\mathrm{SiO}_{2}$, these active factors quickly reacts with the cement hydration generate C-S-H product, it will greatly improve the strength of RPC. When SF content of $8 \%$, the compressive and flexural strength are highest compared with reference RPC, respectively $57.95 \mathrm{MPa}$ and $12.23 \mathrm{MPa}$, 
increase $28.0 \%$ and $45.0 \%$ respectively.

At the same amount of SF replacement of cement $8 \%$, under the same conditions, mechanical activation 15min FA content in different effects on RPC strength shown in Fig.2, $10 \%$ FA specimen strength highest. SF/FA of RPC's $28 \mathrm{~d}$ compressive and flexural strength were $60.68 \mathrm{MPa}$ and $12.30 \mathrm{MPa}$ respectively, than the reference RPC's $28 \mathrm{~d}$ compressive and flexural strength increased by $34.6 \%$ and $45.9 \%$.

\subsection{Silica Fume/Fly Ash to Improve the Durability of RPC and Microscopic Analysis}

\subsection{Silica fume/Fly ash improve RPC impermeability}

Test using concrete chloride ion flux detector measured. The benchmark RPC, SF content is $8 \%$ of RPC and SF/FA of the RPC respectively packed in diameter of $100 \mathrm{~mm}$, thickness of $50 \mathrm{~mm}$ standard circular mold, smooth the surface with a mold, put it aside for $24 \mathrm{~h}$, split mold, after that, put test blocks in the temperature humidity curing box $28 \mathrm{~d}$. Test blocks exposed to air until the surface is dry, wax seal on the cylinder side and placed concrete water-machine intelligent $24 \mathrm{~h}$, remove the specimen surface drying and based on "Concrete chlorine ion flux detector" standard to be tested. Each doing three test blocks, the test results take three test blocks were averaged and converted in accordance with the following formula:

$$
\mathrm{Q}_{\mathrm{s}}=\mathrm{Q}_{\mathrm{x}}(95 / \mathrm{x})^{2}
$$

Qs-- through $95 \mathrm{~mm}$ diameter test piece electric flux (C);

Qx-- diameter by x (mm) of the test piece electric flux (C);

$\mathrm{x}$-- actual diameter test piece ( $\mathrm{mm})$.

After the conversion the following Tab. 3-1:

Tab.3-1 Sf/Fa Of Rpc Impermeability Performance Indicators

\begin{tabular}{|c|c|c|c|c|c|}
\hline \multirow{2}{*}{$\begin{array}{l}\text { The sample } \\
\text { name }\end{array}$} & \multirow{2}{*}{$\begin{array}{l}\text { Time } \\
\text { Step } \\
\text { (min) }\end{array}$} & \multicolumn{2}{|c|}{$\begin{array}{c}\text { Actual measured } \\
\text { results }\end{array}$} & \multirow{2}{*}{$\begin{array}{c}\text { After the } \\
\text { power } \\
\text { conversion } \\
\text { (C) }\end{array}$} & \multirow{2}{*}{$\begin{array}{c}\text { Evaluati } \\
\text { on }\end{array}$} \\
\hline & & $\begin{array}{c}\text { Electric } \\
\text { current } \\
\text { (A) }\end{array}$ & $\begin{array}{l}\text { Power } \\
\text { (C) }\end{array}$ & & \\
\hline Reference RPC & 15 & 2.82 & $\begin{array}{c}2537 . \\
16\end{array}$ & 241.03 & $\begin{array}{c}\text { Moderat } \\
\mathrm{e}\end{array}$ \\
\hline $\begin{array}{c}\text { SF content is } 8 \% \\
\text { of RPC }\end{array}$ & 15 & 2.27 & $\begin{array}{c}2040 . \\
89\end{array}$ & 1938.85 & Low \\
\hline $\mathrm{SF} / \mathrm{FA}$ of RPC & 15 & 2.02 & $\begin{array}{c}1818 . \\
79\end{array}$ & 1727.85 & Low \\
\hline
\end{tabular}

Through Tab.3-1 show that benchmarking RPC, Silica fume content $8 \%$ of RPC and SF/FA mixed of RPC specimens, among them the SF/FA mixed of RPC specimen through the experimental data lower than the reference RPC and Silica fume content is $8 \%$ of RPC specimens significantly. This shows that the SF/FA of RPC its chloride ion impermeability significantly better than the benchmark RPC and single-doped Silica fume RPC . Fly ash and Silica fume composite full play to the micro aggregate filling effect, resulting in 
potential energy density, improve the density of the internal structure of the RPC, reducing harmful hole [1]. Coupled with the fineness of Silica fume is very small, filling the pores of the channel, so the impermeability RPC has greatly improved. On the other hand, SF/FA makes RPC internal pore solution reduces ion concentration, increasing the resistivity of $\mathrm{RPC}$, so improving impermeability and also played a role in retaining rib.

\subsection{Silica fume/Fly ash mixed, influence of RPC pore diameter}

According to the Zhong-wei $\mathrm{Wu}[2]$ the pore diameter the different influence to the strength of concrete. The hole for can be divided into four categories: pore size $<20 \mathrm{~nm}$ hole is harmless, pore size 20 100nm is less harmful hole; Aperture 100 200nm is harmful hole; Pore size $>200 \mathrm{~nm}$ is more harmful hole. Reduce harmful holes in concrete, it will be able to get a higher strength and density.

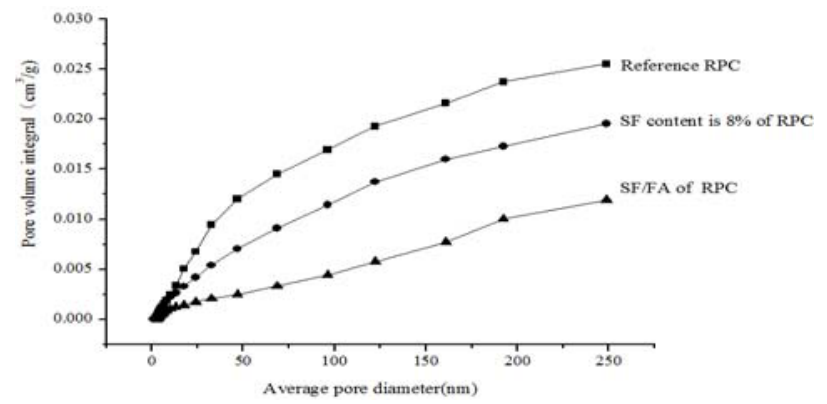

Fig. 3 Different mixing proportion of concrete pore volume distribution points

Comparison of three groups of different mixing proportion in Fig.4 RPC specimens, under the condition of the same aperture of RPC in hole of SF/FA mixed integral volume significantly less than the other two groups. This is because both of Fly ash and Silica fume as active admixture for the existence of the ash, with $\mathrm{Ca}(\mathrm{OH})_{2}$ react at room temperature to generate $\mathrm{C}-\mathrm{S}-\mathrm{H}$. This not only improve the strength of the concrete, and improve the compactness of concrete. Although, the Silica fume contains a lot of activity of $\mathrm{SiO}_{2}$, also meet with $\mathrm{Ca}(\mathrm{OH})_{2}$ to react at room temperature. But the addition of Fly ash can reduce the hydration heat is too large, reduce early temperature rise of cement-based materials, to make up for the drying shrinkage, and wide water shortage. In addition, the particle size of Fly ash and Silica fume is different, more reasonable gradation and good micro aggregate function make the internal structure of the RPC more close-grained, increase the RPC strength and permeability resistance. It also fully embodies the "Synergistic" principle[3,4], $8 \%$ Silica fume and $10 \%$ of Fly ash mixed as the best dosage of compound.

\subsection{SEM analysis}

As a result of the aggregate and cement paste interfacial transition zone water cement ratio is lower than the cement matrix. The weakest link in the concrete, it is caused by the stress of micro cracks produced in the interface transition zone in the first place. Water will continue to spread in the micro cracks in the, in turn, into the interior of the concrete, this will not only reduce concrete mechanics performance and the durability of concrete structure is also very bad. The hydration of Portland cement slurry is homogeneous, especially in the transition region can produce a large amount of harmful pore and bulky crystal. The addition of mineral fine admixture on the one hand can be harmful pore filling, 
dense slurry[5]; On the other hand, with characteristics of active volcanic ash mineral admixtures can react with hydration products of $\mathrm{OH}^{-}$to generate stable hydrated calcium Silicate gel. This will not only improve the mechanical properties of concrete, will greatly improve the durability performance of concrete.
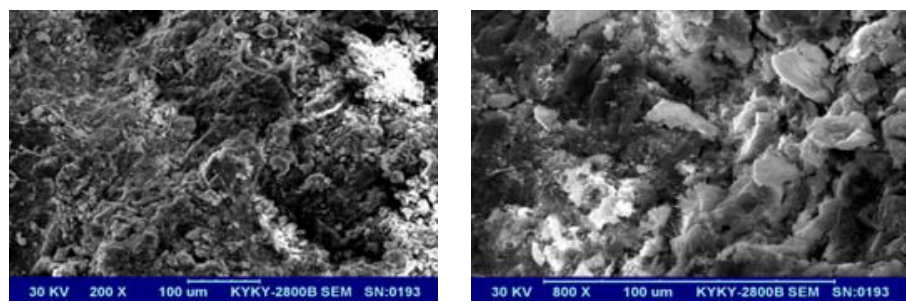

Fig.4 Reference RPC specimens
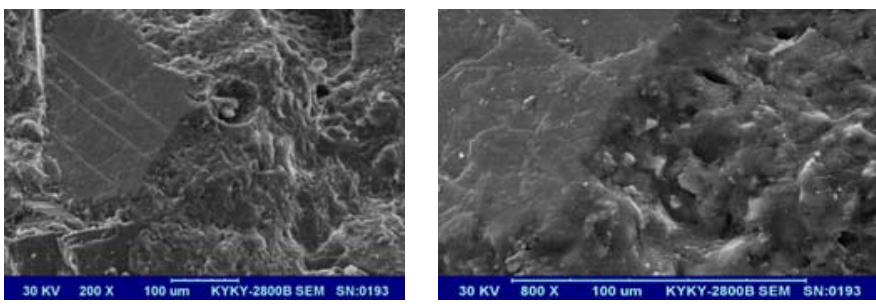

Fig.5 SF/FA of RPC specimens

Compare the magnified 200 times of RPC specimens under SEM figure, SF/FA mixed RPC slurry is very compact, along with the mineral fine admixture, SF and FA, blocking the capillary channel, the transition layer of wool stoma volume rate is significantly reduced, fully embodies the filling effect of mineral fine admixture. Contrast, on the other hand, magnified 800 times of RPC specimens under SEM figure. Benchmark of RPC specimens of aggregate and cement paste of transition band has a lot of unstable and bulky hydration products. And after adding mineral fine admixture of RPC in bulky hydration products close to disappear. Secondary hydration of hydrated calcium Silicate gel well solved the weakest link in the transitional area. Not only increase the RPC strength, but also for durable performance has improved to a great extent.

\section{Conclusion}

Tests proved that when the SF content is $8 \%$, mechanical activation of $15 \mathrm{~min}, 10 \% \mathrm{FA}$ mineral admixtures, incorporation into the RPC. Its $28 \mathrm{~d}$ flexural strength is $12.30 \mathrm{MPa}$, Compressive strength is $60.68 \mathrm{MPa}, 45.9 \%$ and $34.6 \%$ higher than that of benchmark RPC; Thus, SF/FA can greatly improve the mechanical strength of RPC.

Through the determination of chloride ion electric flux meter measuring, SF/FA can reduce the permeability of chloride ion of the mixed, RPC impermeability of the reference index decreased from moderate to low; Through the analysis of pore structure of RPC, SF/FA mixed RPC strength and permeability is obviously better than the performance benchmark RPC and single SF of RPC; combined with the SEM to in-depth analysis of its mechanism, SF/FA mixed good performance of RPC has greatly improved, SF/FA mixed embodies the "Synergistic" principle. 


\section{Acknowledgement}

This work was financially supported by the Jilin Science and Technology Foundation ( No.20140307005SF, No.20150203014SF ).

\section{References}

1. Liguang Xiao, Research of foam concrete block with high volume of Fly ash, J. Jilin Institute of Architecture and Civil Engineering. 19 (2002) 1-5.

2. Zhong-wei $\mathrm{Wu}$, Hui-zhen Lian, Performance concrete, Beijing, China Railway Press, 1999, pp. 94-95.

3. Rui Guo, Domestic research progress on Cement-based materials mixed with compound Fly Ash, Slab and Silica Fume, J .Fly Ash comprehensive utilization. 1.6 (2014) 46-47.

4. Cooma Mehta (USA), Paul JM Montero (US) concrete microstructure, Properties and Materials, Beijing, China Electric Power Press, 2008, pp.77-102.

5. Ming Tang, Hong-liang Liu, Xu-qi Li, With concrete water-cement ratio of cement-slag-fly ash-silica fume compounding effect, J .Concrete .266 (2011) 1-2. 